\title{
Analisis Rasio Keuangan Terhadap Rentabilitas KPRI Obor Guru Kota Bima
}

\author{
M. Firdaus, Wulandari \\ Sekolah Tinggi Ilmu Ekonomi Bima \\ Email: wulan.stiebima@gmail.com \\ Naskah diterima 1 Maret 2020, Revisi 20 Maret 2020, Terbit 19 April 2020 \\ DOI: doi.org/10.21107/pamator.v13i1.6914
}

\begin{abstract}
Abstrak
Penelitian ini bertujuan untuk menjelaskan pengaruh modal kerja,likuiditas dan solvabilitas terhadap rentabilitas pada KPRI obor Guru Kota Bima periode tahun 2014-2019. Populasi penelitian ini adalah laporan Keuangan dan neraca periode tahun 1966-2019. Sampel diambil dengan menggunakan metode purposive sampling sehingga diperoleh 6 tahun penelitian yang memenuhi syarat sebagai sampel. Penelitian ini menggunakan data sekunder dan metode analisis regresi berganda. Hasil penelitian menunjukkan bahwa variabel modal kerja berpengaruh negatif dan tidak signifikan terhadap rentabilitas, variabel likuiditas berpengaruh positif dan tidak signifikan terhadap rentabilitas, variabel solvabilitas berpengaruh negatif dan tidak signifikan terhadap rentabilitas. Secara simultan variabel modal kerja, likuiditas dan solvabilitas tidak berpengaruh signifikan terhadap rentabilitas
\end{abstract}

Kata kunci : modal kerja, likuiditas, solvabilitas, rentabilitas

\begin{abstract}
This study aims to explain the effect of working capital, liquidity and solvency on rentability on the KPRI torch Bima City Teachers for the period 2014-2019. The population of this research is the financial statements and balance sheets for the period 1966-2019. Samples were taken using a purposive sampling method to obtain 6 years of research that met the requirements as samples. This study uses secondary data and multiple regression analysis methods. The results showed that the variable of working capital had a negative and not significant effect on rentability, the liquidity variable had a positive and not significant effect on profitability, the solvency variable had a negative effect and was not significant on rentability. Simultaneously the variables of working capital, liquidity and solvency have no significant effect on profitability

Key Words: working capital, liquidity, solvency, profitability
\end{abstract}

\section{PENDAHULUAN}

Koperasi Pegawai Republik Indonesia (KPRI) OBOR guru Kota Bima adalah koperasi guru-guru Pegawai Republik Indonesia. Anggotanya adalah pegawaipegawai yang tersebar diseluruh wilayah Kota Bima dimana kegiatan usahanya adalah simpan pinjam dan usaha penjualan sembako.

Indikator kinerja keuangan perusahaan termasuk koperasi agar dapat terus berjalan diperlukan adanya suatu laba. Akan tetapi karena koperasi berwatak sosial maka mencari laba bukan untuk perseorangan tetapi untuk kemakmuran seluruh anggotanya. Oleh karena itu, koperasi perlu memperhatikan posisi kinerja keuangannya agar koperasi dapat terus menjalankan aktivitas operasionalnya supaya kelangsungan usaha koperasi tetap terus terjaga. Alat-alat yang digunakan untuk menganalisis laporan keuangan adalah dengan menggunakan analisis modal Kerja dan analisis rasio keuangan yang meliputi likuiditas, solvabilitas dan rentabilitas.

Berdasarkan data yang diperoleh dari laporan keuangan dan neraca, total aktiva pada KPRI Obor Kota Bima selama 4 tahun terakhir mengalami fluktuatif. Hal ini dilihat dari tahun 2016 total aktiva mengami peningkatan, kemudian di tahun 2017 mengalami menurunan, penurunan ini di disebakan karena banyak anggota koperasi yang keluar dan pensiun. Pada 2018 dan 2019 kembali mengalami kenaikan. Sedangkan dari sisi total hutang pada tahun 2016 dan 2019 mengalami 
kenaikan. Kenaikan ini disebabkan peningkatan hutang jangka pendek dan hutang jangka panjang dan ditahun 2017 dan 2018 kembali mengalami penurunan Laba Koperasi ikut mengalami kondisi yang terus mengalmi fluktuatif disebabkan karena biaya operasional yang tidak menentu

\section{METODOLOGI}

Jenis Penelitian

Jenis penelitian ini termasuk penelitian asosiatif (pengaruh). Penelitian Asosiatif merupakan suatu pernyataan yang menunjukkan dugaan tentang hubungan antara dua variabel atau lebih (Sugiyono, 2008). Penelitian ini mencari pengaruh antara modal kerja $\left(X_{1}\right)$, likuiditas $\left(X_{2}\right)$, solvabilitas $\left(X_{3}\right)$ terhadap rentabilitas $(Y)$.

\section{a. Instrumen Penelitian}

Instrumen merupakan alat yang digunakan sebagai pengumpul data dalam penelitian (Siregar, 2014). Dalam penelitian ini alat yang digunakan adalah daftar tabel laporan keuangan yang terdiri dari masingmasing indikator variabel penelitian.

\section{b. Populasi dan Sampel Penelitian}

Populasi merupakan keseluruhan kumpulan elemen-elemen yang berkaitan dengan apa yang peneliti harapkan dalam mengambil beberapa kesimpulan. Populasi dalam penelitian ini seluruh laporan keuangan tahunan KPRI obor Guru Kota Bima 1966 sampai dengan tahun 2019 (53) tahun. Sampel adalah bagian dari jumlah maupun karakteristik yang dimiliki oleh populasi dan dipilih secara hati-hati dari populai tersebut (Ikhsan, 2014).

Teknik pengambilan sampel yang digunakan adalah purposive sampling. yaitu tekhnik sampling dengan menggunakan pertimbangan dan batasan tertentu dengan tujuan untuk mendapatkan sampel yang relevan dengan tujuan penelitian dan representatif sesuai dengan kriteria yang tertentu (Sanusi, 2013). Kriteria yang digunakan untuk memilih sampel adalah data yang tersedia lengkap (data secara keseluruhan tersedia pada koperasi periode 31 Desember 2014 sampai dengan 31 Desember 2019). Teknik pengumpulan data yang digunakan adalah observasi, dokumentasi dan studi pustaka.

\section{c. Lokasi dan Waktu Penelitian}

Penelitian ini dilakukan dikoperasi KPRI Obor Guru Kota Bima yang berlokasi di jalan Sultan Kaharuddin Kompleks Pertokoan Kota Bima Provinsi Nusa Tenggara Barat.

\section{d. Jenis dan Sumber Data}

Jenis data yang penulis gunakan adalah jenis data kuantitatif yaitu data yang berbentuk angka atau data kualitatif yang diangkakan (Puguh, 2016). Sumber data yang diperoleh dalam penelitian ini menggunakan sumber data sekunder yang diperoleh dari KPRI Obor Guru Kota Bima berupa laporan keuangan dari tahun 2014 sampai dengan tahun 2019.

\section{Teknik Analisis Data}

a. Modal Kerja, menggunakan rumus sebagai berikut :

Modal kerja = Aktiva lancar - Utang lancar

b. Likuiditas, mengunakan Rumus Current Ratio sebagai berikut :

$$
\text { Current Ratio }=\frac{\text { Aktiva Lancar }}{\text { Hutang Lancar }}
$$

c. Solvabilitas, mengunakan Rumus Debt to Total Asset sebagai berikut :

$$
\text { Debt to Total Asset }=\frac{\text { Total Hutang }}{\text { Total Aktiva }}
$$

d. Rentabilitas, mengunakan Rumus Return On Assets sebagai berikut :

$$
R O A=\frac{\text { Laba sebelum Pajak }}{\text { Total Aktiva }} \times 100 \%
$$

\section{Analisis Statistik}

Statistik deskriptif merupakan statistik yang mengambarkan fenomena atau karakteristik distribusinya (Jogiyanto, 2010). Statistik deskriptif bertujuan untuk menggambarkan ringkasan data-data penelitian seperti mean, maksimum, minimum, dan standar deviasi. Uji asumsi klasik digunakan untuk memastikan bahwa sampel yang diteliti terbebas dari gangguan normalitas, multikolinieritas, autokorelasi dan heterokedastisitas. Uji normalitas digunakan untuk menguji apakah model regresi mempunyai distribusi normal ataukah tidak.

Uji Multikolinearitas digunakan untuk mengetahui apakah dalam model regresi ditmukan adanya korelasi antara variabel bebas atau tidak. Dikatakan tidak terjadi multikolinieritas apabila nilai tolerance $\geq 0,10$ dan nilai VIF $\leq 10$. Dikatakan terdapat multikolinieritas apabila nilai tolerance $\leq 0,10$ 
dan nilai VIF $\geq 10$ (Santoso dalam Komala, 2014).

Uji Autokorelasi digunakan untuk mendeteksi autokorelasi, dapat dilakukan uji Durbin Watson (Ghozali, 2016). Untuk menentukan autokorelasi bisa diambil patokan sebagai berikut : Jika $\mathrm{d}<\mathrm{dL}$, terdapat autokorelasi positif; jika d>dU maka tidak terdapat autokorelasi positif; jika $\mathrm{dL}<\mathrm{d}<\mathrm{dU}$ maka pengujian tidak meyakinkan atau tidak ada kesimpulan.

\section{Analisis Regresi Linear Berganda}

Regresi linier berganda merupakan analisis untuk menguji hubungan linier antara dua atau lebih variabel independent $\left(\mathrm{X}_{1}, \mathrm{X}_{2}, \mathrm{X}_{3}\right)$ terhadap variabel dependent $(\mathrm{Y})$ (Sulistiono, 2014), dengan persamaan :

Keterangan :

$$
\hat{Y}=\alpha+\beta 1 X 1+\beta 2 X 2+\beta 3 X 3
$$

$\mathrm{Y}=$ Rentabilitas,

$\mathrm{X} 1=$ Modal kerja,

$\mathrm{X} 2=$ Likuiditas,

X3 = Solvabilitas,

$\beta 1, \beta 2, \beta 3=$ Koefisien regresi dari $X_{1}, X_{2}, X_{3}$

$$
\alpha=\text { Konstanta }
$$

Analisis koefisien korelasi dalam penelitian ini digunakan untuk menunjukkan arah hubungan antara variable Modal kerja dan variabel Likuiditas dan variabel Solvabilitas terhadap variabel Rentabilitas. Koefisien determinasi $\left(R^{2}\right)$ pada dasarnya digunakan untuk mengukur besarnya kontribusi atau pengaruh variabel bebas terhadap variasi naik turunnya variabel terikat. Nilai koefisien determinasi berada antara 0 sampai 1. Dengan kata lain, koefisien determinasi merupakan kemampuan variabel $X$ dalam menjelaskan variabel Y (Sulistiono, 2014).

Hipotesis Simultan (Uji F) digunakan untuk menguji variabel independen secara bersama-sama (simultan) terhadap variabel dependen, persamaannya adalah sebagai berikut :

$$
\mathrm{Fh}=\frac{\mathrm{R}^{2} / \mathrm{k}}{\left(1-\mathrm{R}^{2}\right) /(\mathrm{n}-\mathrm{k}-1)}
$$

Keterangan :

$\mathrm{R}^{2} \quad=$ nilai $\mathrm{R}^{2}$ dari hasil estimasi regresi parsial variabel independen.

$\mathrm{n} \quad=$ jumlah sampel

$\mathrm{k} \quad=$ jumlah variabel independen
Uji Hipotesis (Uji t) untuk mengetahui seberapa besar pengaruh suatu variabel independent secara individual dalam menerangkan variabel dependent

Dimana :

$$
\mathrm{t}=\frac{\mathrm{r}_{\mathrm{p}} \sqrt{\mathrm{n}-3}}{\sqrt{1-\mathrm{r}_{\mathrm{p}}^{2}}}
$$

$$
\begin{array}{ll}
\mathrm{t} & : \text { Nilai uji t } \\
r_{p} & : \text { Koefisien korelasi } \\
r^{2} & : \text { Koefisien determinasi } \\
n & : \text { Banyaknya sampel observasi }
\end{array}
$$

\section{HASIL DAN PEMBAHASAN}

\section{Analisis Data Penelitian}

Hasil analisis output diatas menjelaskan bahwa jumlah data $(\mathrm{N})$ masing-masing pada variabel Modal kerja, likuiditas solvabilitas dan rentabilitas adalah 6 tahun dan semuanya dinyatakan valid. Ini berarti, tidak ada data yang tidak valid/hilang (missing). Nilai Rata-rata untuk $X_{1}$ adalah 23,10 , nilai rata-rata untuk $X_{2}$ adalah 9,63 dan nilai rata-rata untuk $X_{3}$ adalah 28,85 sedangkan variabel $Y$ adalah sebesar 13,54 (Tabel 1).

Tabel 1. Statistik Deskriptif

\begin{tabular}{|c|r|r|c|}
\hline & Mean & Std. Deviation & N \\
\hline Y & 13.5467 & 2.12428 & 6 \\
X1 & 23.1050 & .08408 & 6 \\
X2 & 9.6387 & 122.19660 & 6 \\
X3 & 28.8533 & 5.45062 & 6 \\
\hline
\end{tabular}

Uji Asumsi Klasik

a. Uji Normalitas

Berdasarkan probability plot dibawah dapat diketahui bahwa titik-titik residual menyebar di sekitar garis diagonal. Hal ini berarti residual dinyatakan berdistribusi normal. Dengan demikian asumsi normalitas terpenuhi.

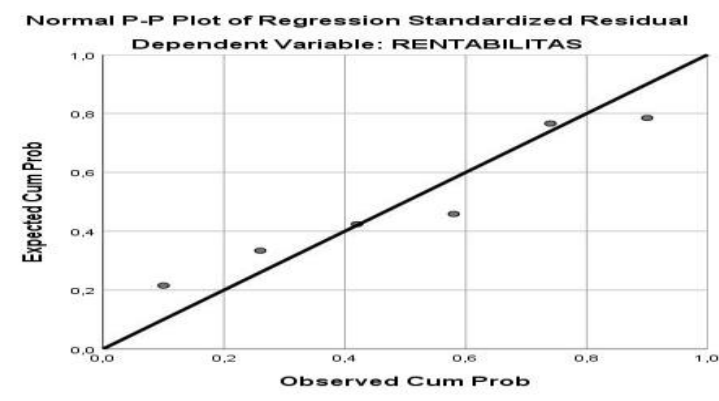

Gambar 1. Grafik Probability Plot 
b. Uji Multikolinearitas

Pengujian multikolinearitas dilakukan dengan melihat nilai VIF dan nilai Tolerance. Jika nilai VIF tidak lebih besar dari 10 dan nilai Tolerance tidak kurang dari 0,1 maka hal ini menunjukkan tidak terjadi problem multikolineritas.

Tabel 2. Hasil Uji Multikolinearitas

\begin{tabular}{|l|r|r|}
\hline \multirow{2}{*}{ Variabel Independen } & \multicolumn{2}{|c|}{ Collinearity Statistics } \\
\cline { 2 - 3 } & Tolerance & \multicolumn{1}{c|}{ VIF } \\
\hline Modal Kerja & .117 & 8,512 \\
\hline Likuiditas & .245 & 4,068 \\
\hline Solvabilitas & .166 & 6,021 \\
\hline
\end{tabular}

Berdasarkan tabel di atas dapat dilihat bahwa nilai semua VIF $<10$ dan tolerance sebesar > 0,1 maka dapat dinyatakan tidak terjadi multikolinearitas.

\section{c. Uji Autokorelasi}

Salah satu cara untuk mendeteksi masalah autokorelasi adalah dengan melihat nilai Durbin-Watson. Tabel Durbin Watson menunjukkan $\mathrm{n}=6, \mathrm{k}=3$, diperoleh, $\mathrm{dU}=$ 2,2866, 4 - Du = 1.7134 Berdasarkan autput di atas, diketahui nilai DW sebesar 1.783 yang berarti 2,2866 > 1,783< 11.7134 maka dapat disimpulkan bahwa tidak terdapat gejala autokorelasi.

Tabel 3. Uji Autokorelasi

\begin{tabular}{|l|c|r|r|r|r|}
\hline Model & $\mathrm{R}$ & $\begin{array}{c}\mathrm{R} \\
\text { Square }\end{array}$ & $\begin{array}{c}\text { Adjusted R } \\
\text { Square }\end{array}$ & $\begin{array}{c}\text { Std. Error } \\
\text { of the } \\
\text { Estimate }\end{array}$ & $\begin{array}{c}\text { Durbin- } \\
\text { Watson }\end{array}$ \\
\hline 1 & $.910^{\mathrm{a}}$ & .829 & .572 & 1,38921 & 1,783 \\
\hline
\end{tabular}

a. Predictors: (Constant), X3 X2, X1;

b. Dependent Variable : $Y$

Uji Regresi Linear Berganda

\begin{tabular}{|}
\hline Tabel 4. Hasil Uji Regresi Linier Berganda \\
\hline \multirow{2}{*}{\begin{tabular}{|r|r|r|r|r|r|} 
Mnstandardized \\
Coefficients
\end{tabular}} & $\begin{array}{r}\text { Standar } \\
\text { dized } \\
\text { Coefficie } \\
\text { nts }\end{array}$ & & \\
\cline { 2 - 6 } & B & $\begin{array}{r}\text { Std. } \\
\text { Error }\end{array}$ & Beta & t & Sig. \\
\hline 1 & Constant & 611,411 & 501,275 & & 1,220 &, 347 \\
\hline X1 & $-26,572$ & 21,744 & $-1,043$ & $-1,222$ &, 346 \\
\hline X2 &, 025 &, 010 & 1,457 & 2,464 &, 133 \\
\hline X3 &,- 285 &, 280 &,- 732 & $-1,020$ &, 415 \\
\hline
\end{tabular}

Uji regresi linear berganda bertujuan untuk menghitung besarnya pengaruh dua atau lebih variabel bebas terhadap variabel terikat. Berdasarkan Tabel dapat dirumuskan persamaan regresi linear berganda adalah sebagai berikut :

$Y=611,411-26,572 X_{1}+0,025 X_{2}-0,285 X_{3}$

\section{Pengujian Hipotesis}

a. Koefisien Determinasi

Koefisien determinasi $\left(R^{2}\right)$ pada dasarnya digunakan untuk mengukur besarnya kontribusi atau pengaruh variabel bebas terhadap variasi naik turunnya variabel terikat.

Tabel 5. Uji Determinasi $\left(R^{2}\right)$

\begin{tabular}{|c|c|c|c|c|}
\hline Model & $\mathrm{R}$ & $\mathrm{R}$ Square & $\begin{array}{c}\text { Adjusted R } \\
\text { Square }\end{array}$ & $\begin{array}{c}\text { Std. Error of } \\
\text { the Estimate }\end{array}$ \\
\hline 1 & $.910^{\mathrm{a}}$ & .829 & .572 & 1,38921 \\
\hline
\end{tabular}

a. Predictors: (Constant), X3 X2, X1;

b. Dependent Variable : $Y$

Dari tabel diatas dapat dilihat nilai $R^{2}$ sebesar 0,829 atau $82,9 \%$ yang berarti bahwa $82,9 \%$ current ratio dapat dijelaskan oleh Modal kerja, Likuiditas dan Solvabilitas Sedangkan $17,1 \%$ sisanya dapat dijelaskan oleh variabel-variabel lain yang tidak diteliti pada penelitian ini.

b. Uji F (Pengujian Simultan)

Uji $F$ pada dasarnya menunjukkan apakah semua variabel bebas yang dimaksudkan dalam model mempunyai pengaruh secara bersama-sama (serentak) terhadap variabel terikat. Pengujian ini dilakukan dengan menghitung serta membandingkan $F_{\text {hitung }}$ dengan $F_{\text {tabel }}$. Tabel 6. Hasil Uji Simultan (Uji F)

\begin{tabular}{|c|c|c|c|c|c|}
\hline Model & $\begin{array}{l}\text { Sum of } \\
\text { Squares }\end{array}$ & df & $\begin{array}{l}\text { Mean } \\
\text { Square }\end{array}$ & $F$ & Sig. \\
\hline Regression & 18,703 & 3 & 6,234 & 3,23 & $245^{b}$ \\
\hline Residual & 3,860 & 2 & 1,930 & & \\
\hline Total & 22,563 & 5 & & & \\
\hline
\end{tabular}

a. Predictors: (Constant), $\mathrm{X} 3 \mathrm{X} 2, \mathrm{X} 1$;

b. Dependent Variable : $Y$

Berdasarkan tabel diatas diperoleh nilai fhitung sebesar 3,230 dengan tingkat signifikan 0,245 . Diketahui bahwa nilai $F_{\text {hitung }}$ $(3,230)<F_{\text {tabel }}(9,28)$ dan tingkat signifikan 0,245 lebih besar dari tingkat signifikan 0,05. Maka dapat disimpulkan bahwa tidak terdapat pengaruh modal kerja, likuiditas, 
dan solvabilitas terhadap rentabilitas secara simultan pada KPRI Obor guru Kota bima ( $\mathrm{H}_{0}$ diterima).

\section{c. Uji t (Uji Parsial)}

Uji $t$ persial ini ditujukan untuk mengetahui ada dan tidaknya pengaruh dari setiap variabel bebas terhadap variabel terikat. Pengujian signifikansi individual ini df $=\mathrm{n}-\mathrm{k}-1=6-3-1=2$ maka t tabel $=(4,303)$. Berdasarkan Analisis diperoleh nilai $t_{\text {hitung }}$ untuk modal kerja sebesar -1,222 dengan tingkat signifikan 0,346 . Diketahui bahwa nilai $t_{\text {hitung }}(-1,222)<t_{\text {tabel }}(4,303)$ dan tingkat signifikan 0,346 lebih besar dari tingkat signifikan 0,05. Maka dapat disimpulkan bahwa $\mathrm{H}_{01}$ diterima, dan $\mathrm{H}_{\mathrm{a}}$ ditolak artinya tidak terdapat pengaruh modal kerja terhadap rentabilitas.

Nilai $t_{\text {hitung }}$ untuk likuiditas sebesar 2,464 dengan tingkat signifikan 0,133 . Diketahui bahwa nilai $t_{\text {hitung }}(2,464)<t_{\text {tabel }}(4,303)$ dan tingkat signifikan 0,133 lebih besar dari tingkat siginfikan 0,05. Maka dapat disimpulkan bahwa $\mathrm{H}_{02}$ diterima dan $\mathrm{H}_{a}$ ditolak, artinya tidak terdapat pengaruh Likuiditas terhadap rentabilitas.

Nilai $t_{\text {hitung }}$ untuk solvabilitas sebesar 1,020 dengan tingkat signifikan 0,415. Diketahui bahwa nilai $t_{\text {hitung }}(-1,020)<t_{\text {tabel }}$ $(4,303)$ dan tingkat signifikan 0,415 lebih besar dari tingkat siginfikan 0,05. Maka dapat disimpulkan bahwa $\mathrm{H}_{03}$ diterima dan $\mathrm{H}_{\mathrm{a}}$ ditolak, artinya tidak terdapat pengaruh solvabilitas terhadap rentabilitas.

\section{KESIMPULAN}

Berdasarkan hasil analisis data dan pembahasan yang telah dijelaskan sebelumnya maka dapat disimpulkan beberapa hal sebagai berikut :

1. Berdasarkan hasil penelitian uji $\mathrm{t}$, dapat diketahui bahwa variabel Modal Kerja secara parsial berpengaruh negatif dan tidak signifikan terhadap Rentabilitas .

2. Berdasarkanhasil penelitian uji t, dapat diketahui bahwa variabel Likuiditas secara parsial berpengaruh positif dan tidak signifikan terhadap Rentabilitas.

3. Berdasarkan hasil penelitian uji $t$, dapat diketahui bahwa variabel Solvabilitas secara parsial berpengaruh negatif dan tidak signifikan terhadap Rentabilitas.

4. Berdasarkan hasil penelitian uji F, dapat diketahui bahwa variabel Modal Kerja,
Likuiditas dan Solvabilitas secara simultan (bersama-sama) tidak berpengaruh signifikan terhadap Rentabilitas.

Berdasarkan hasil penelitian diatas, peneliti memberikan saran yang diharapkan mampu menjadi penambah informasi bagai pihak yang berkepentingan antara lain :

1. Untuk peneliti selanjutnya, diusahakan perusahaan yang menjadi sampel penelitian bisa dibedakan dari penelitian ini. Mungkin dengan sampel penelitian pada perusahaan yang diambil maka variabel likuiditas, dan solvabilitas. Meskipun dalam penelitian ini variabel likuiditas tidak berpengaruh secara parsial terhadap profitabilitas.

2. Manajemen perusahaan harus memperhatikan solvabilitasnya. Untuk itu manajemen perusahaan harus bisa menjaga dengan baik modal kerja, likuiditas dan solvabilitasnya agar mampu menghasilkan rentabilitas / laba yang diharapkan koperasi.

\section{DAFTAR PUSTAKA}

Ghozali, I. 2016, Aplikasi Analisis Multivariate Dengan Program (IBM SPSS). Edisi 8. Badan Penerbit Universitas Diponegoro. Semarang.

Hery. 2016. Analisis Kinerja Manajemen, Jakarta : Penerbit : Grasindo.

Wulandari, I.S \& Yunita, I. 2016. Pengaruh Modal Kerja, Struktur Aktiva, Likuiditas \& Solvabilitas Terhadap Rentabilitas.

Ikhsan. 2014. Metodologi Penelitian Bisnis, Bandung : Citapustaka Media.

Indriantoro, N \& Supomo, B. 2014. Metodologi Penelitian Bisnis untuk Akuntansi dan Manajemen. Edisi Pertama. Yogyakarta: BPFE.

Jogiyanto, 2010. Metodologi Penelitian Bisnis. Yogyakarta. BPFE.

Munawir. 2017. Analisis Laporan Keuangan. Edisi 4. Yogyakarta: Liberty. 
Prihadi, T. 2013, Analisis Laporan Keuangan : Teori dan Aplikasi. Jakarta : Pusat: Penerbit PPM.

Puguh, S. 2016. Metode Penelitian Kuantitatif Untuk Bisnis: Pendekatan Filosofi dan Praktis, Jakarta : PT Indeks.

Sanusi A., 2013. Metode Penelitian Bisnis, Jakarta : Salemba Empat.

Siregar, S. 2014. Statistik Parametrik Untuk Penelitian Kuantitatif, Jakarta: Bumi Aksara.

Subramanyam, K. R \& John J. Wild. 2013. Analisis Laporan Keuangan. Edisi 10. Buku Dua. Yang Dialihbahasakan oleh Dewi Yanti. Jakarta: Salemba Empat.
Sugiono. 2017. Metode Penelitian Kuantitatif, Kualitattif dan $R \& D$. Bandung : Alfabeta.

Taruh, V. 2012. Analisis Rasio Keuangan Dalam Memprediksi Pertumbuhan Laba pada Perusahaan Manufaktur di Bursa Efek Indonesia (BEI): Jurnal PELANGI IImu Vol 5 No.1.

Van Horne, J.C \& Wachowics, J.M. 2012. Prinsip-Prinsip Manajemen Keuangan. Edisi 13 Buku 1. Diterjemahkan oleh Quratul'ain Mubarakah. Jakarta : Salemba Empat. 